\title{
PENDIDIKAN KESEHATAN REPRODUKSI REMAJA DI SMPN 52 SURABAYA
}

\author{
Hanifa Fitriana ${ }^{1}$, Pulung Siswantara ${ }^{2}$ \\ ${ }^{1,2}$ Departemen Promosi Kesehatan dan Ilmu Perilaku, \\ Fakultas Kesehatan Masyarakat, Universitas Airlangga \\ Alamat Korespondensi: Hanifa Fitriana \\ E-mail: hanifa.fitriana-2015@fkm.unair.ac.id
}

\begin{abstract}
Teenager is a period of rapid physical, psychological and intellectual development. Adolescents tend to like challenges without careful consideration. This caused various problems of adolescents, especially in reproductive health. Adolescent Reproductive Health (ARH) Education by teachers is an effort to overcome the problem of reproductive health of students. The purpose of this research was to identify the transfer process of adolescent reproductive health education at SMPN 52 Surabaya. This research used observational case study research with qualitative approach. Informants in this study consisted of teachers and students. Data was collected through in-depth interviews and document studies. This study found that most teacher informants have poor understanding of comprehensive ARH. The teacher informants said that ARH education is the responsibility of parents, school, community and government. The teacher informants delivered the ARH material with various methods. Teacher separated male and female students during delivering process of sensitive ARH materials. This method can encourage students' activeness to ask questions to the teachers. A better understanding of teachers on KRR materials can improve the quality of students' material delivery.ARH education is not only the responsibility of the school, but also family, community to government. The government needs to provide training for teachers related to theARH education. Families need to provide ARH education at home, meanwhile the community needs to provide supervision for adolescents in their neighborhood.
\end{abstract}

Keywords: adolescent, education, reproductive health

\begin{abstract}
ABSTRAK
Remaja mengalami perkembangan fisik, psikologis dan intelektual yang pesat. Remaja cenderung menyukai tantangan tanpa pertimbangan yang matang. Hal tersebut menimbulkan berbagai permasalahan pada remaja, khususnya permasalahan kesehatan reproduksi. Pendidikan Kesehatan Reproduksi Remaja (KRR) oleh guru merupakan suatu upaya untuk mengatasi masalah kesehatan reproduksi siswa. Tujuan dari penelitian ini adalah mengidentifikasi penyampaian materi kesehatan reproduksi remaja di SMPN 52 Surabaya. Penelitian ini merupakan penelitian studi kasus observasional dengan pendekatan kualitatif. Informan dalam penelitian ini terdiri dari guru dan siswa. Pengumpulan data melalui wawancara mendalam dan studi dokumen. Penelitian ini mengungkapkan bahwa sebagian besar informan guru kurang memahami KRR komprehensif. Informan guru menyatakan bahwa pendidikan KRR adalah tanggung jawab orang tua, sekolah, masyarakat dan pemeritah. Informan guru menyampaikan materi KRR dengan berbagai metode. Saat menyampaikan materi KRR yang sensitif, guru memisahkan siswa laki-laki dan perempuan. Metode tersebut dapat meningkatkan keaktifan siswa untuk tanya-jawab dengan guru. Pemahaman guru mengenai materi KRR yang semakin baik dapat meningkatkan kualitas penyampaian materi pada siswa. Pendidikan KRR bukan hanya menjadi tanggung jawab sekolah, namun perlu mendapatkan dukungan dari keluarga, masyarakat hingga pemeritah. Pemerintah perlu memberikan pelatihan pada guru terkait pendidikan KRR. Keluarga perlu memberikan pendidikan KRR di rumah, sedangkan masyarakat perlu memberikan pengawasan pada remaja di lingkungannya.
\end{abstract}

Kata kunci: remaja, pendidikan, kesehatan reproduksi

\section{PENDAHULUAN}

$\begin{array}{lcr}\text { Menurut } & \text { BKKBN (2013) } & \text { remaja } \\ \text { mengalami } & \text { pertumbuhan } & \text { dan } \\ \text { perkembangan pesat pada aspek fisik, } \\ \text { psikologis dan juga intelektual. Beberapa }\end{array}$

karakteristik remaja yaitu memiliki keingintahuan yang besar, menyukai petualangan dan tantangan serta berani menanggung risiko atas perbuatannya tanpa didahului oleh pertimbangan yang matang. Hal ini menimbulkan banyak 
permasalahan pada remaja, salah satunya adalah permasalahan mengenai kesehatan reproduksi.

Kesehatan reproduksi merupakan keadaan sehat fisik, mental, dan sosial secara utuh, tidak hanya bebas dari penyakit atau kecacatan yang berkaitan dengan sistem, fungsi, dan proses reproduksi. Sedangkan Kesehatan Reproduksi Remaja (KRR) merupakan bagian terpadu dari program kesehatan dan keluarga berencana di Indonesia. Program terpadu ini secara khusus bertujuan untuk mengatasi masalah terkait pernikahan dini, kehamilan tidak diinginkan, konsumsi tembakau dan alkohol, serta HIV-AIDS (Kemenkes, 2015).

Berdasarkan data dari KPAI (2016) menunjukkan bahwa jumlah kasus anak dan remaja sebagai korban prostitusi online di Indonesia adalah sebanyak 83 kasus pada tahun 2014 dan 117 kasus pada tahun 2015. Sedangkan kasus anak sebagai korban Eksploitasi Seks Komersial Anak (ESKA) adalah sebanyak 46 kasus pada tahun 2014 dan 72 kasus pada tahun 2015. Kasus pornografi dan cyber cryme pada anak adalah sebanyak 322 kasus pada tahun 2014, 463 kasus pada tahun 2015 dan 315 kasus pada Januari-Juli tahun 2016. Komisioner KPAI Jasra Putra mengungkapkan, data menunjukkan bahwa pihaknya menemukan 218 kasus kekerasan seksual anak pada tahun 2015. Sementara pada 2016, KPAI mencatat terdapat 120 kasus kekerasan seksual terhadap anakanak. Kemudian pada tahun 2017 tercatat sebanyak 116 kasus. Banyaknya jumlah kasus anak dan remaja tersebut tidak dapat ditangani tanpa adanya kerjasama dengan berbagai pihak. Noviana (2015) menyebutkan bahwa penanganan kekerasan seksual terhadap anak memerlukan kerjasama antara keluarga, masyarakat dan pemerintah.

BKKBN (2013) mengungkapkan bahwa remaja yang mengaku mempunyai teman yang pernah melakukan hubungan seksual pranikah usia 14-19 tahun sebesar $34,7 \%$ perempuan dan $30,9 \%$ laki-laki.
Hasil Riset Kesehatan Dasar tahun 2013 terdapat sebanyak 2,6\% perkawinan pertama dilakukan pada usia kurang dari 15 tahun dan $23,9 \%$ usia perkawinan pertama berada pada usia 15-19 tahun. Angka kehamilan pada remaja umur kurang 15 tahun adalah sebesar $0,02 \%$ dan kehamilan pada usia 15-19 tahun sebesar 1,97\% (Kemenkes, 2015). Hal tersebut menunjukkan kesadaran anak dan remaja terhadap pentingnya kesehatan reproduksi remaja di Indonesia masih jauh tertinggal.

Kemenkes (2015) menyatakan bahwa sekitar 33,3\% remaja perempuan dan $34,5 \%$ remaja laki-laki yang berusia 15-19 tahun mulai berpacaran pada saat mereka belum berusia 15 tahun. Pada usia tersebut dikhawatirkan remaja belum memiliki keterampilan hidup yang memadai, sehingga mereka memiliki resiko untuk melakukan seks pranikah. Hasil survei yang dilakukan BKKBN (2011) di Surabaya menyebutkan bahwa sekitar 54\% remaja wanita belum menikah telah kehilangan keperawanannya. Hal ini menunjukkan bahwa Surabaya memiliki permasalahan kesehatan reproduksi remaja yang cukup besar.

Sebagian besar anak dan remaja yang berusia 5-19 tahun terpapar dengan lembaga pendidikan dalam jangka waktu cukup lama. Kemenkes (2015) menyatakan partner diskusi tentang kesehatan reproduksi yang paling disukai remaja berturut-turut adalah teman sebaya, guru, dan ibu. Berdasarkan data tersebut maka sekolah merupakan lembaga potensial untuk penyampaian pendidikan KRR. Guru memiliki peran penting dalam pendidikan, sehingga pengetahuan dan pemahaman guru mengenai materi pembelajaran menjadi kunci dalam keberhasilan proses pendidikan. Selain menyampaikan materi pembelajaran di dalam kelas, guru juga memiliki tugas untuk mendidik siswa menjadi pribadi yang lebih baik. Oleh karena itu guru juga memiliki peran dalam pembentukan karakter peserta didik. 
Utomo dan McDoland (2009) menyatakan bahwa program pendidikan seksualitas dan kesehatan reproduksi di Indonesia belum komprehensif. Hal tersebut dikarenakan pendidikan seksualitas dan kesehatan reproduksi di Indonesia lebih fokus pada aspek biologis dan pencegahan penyakit menular. Penelitian Pakasi dan Kartikawati (2013) menyatakan bahwa pendidikan kesehatan reproduksi dan seksualitas dianggap penting untuk diajarkan, namun masih terdapat anggapan bahwa pendidikan ini tabu bila dibicarakan secara publik, selain itu terdapat kekhawatiran pendidikan ini dapat membuat remaja ingin mengetahui dan mendorong untuk melakukan seks pranikah. Berdasarkan data tersebut peneliti tertarik untuk mengidentifikasi penyampaian materi kesehatan reproduksi remaja oleh guru pada salah satu SMP Surabaya.

\section{METODE PENELITIAN}

\section{Penelitian ini adalah penelitian studi kasus observasional dengan pendekatan kualitatif deskriptif. Desain penelitian yang digunakan oleh peneliti adalah studi kasus. Hal tersebut dikarenakan setiap objek penelitian memiliki keunikan tersendiri (Irawan, 2006).}

Informan dalam penelitian ini ditentukan dengan cara purposive sampling. Menurut Irawan (2006), sampel purposif adalah sampel yang sengaja dipilih oleh peneliti dikarenakan sampel memiliki ciri-ciri tertentu yang dapat memperkaya penelitian. Informan dalam penelitian ini terdiri dari guru dan siswa. Kriteria inklusi informan guru adalah guru mata pelajaran yang terkait dengan fisik dan sosial dan bersedia menjadi informan penelitian. Informan siswa dalam penelitian ini berasal dari kelas IX. Kriteria inklusi informan siswa adalah siswa yang menyimak dalam kegiatan belajar mengajar dengan baik, bersedia menjadi informan penelitian, dan harus mendapatkan ijin dari wali murid. Penelitian dilaksanakan di SMPN 52 Surabaya pada bulan Mei-Oktober 2017.

$$
\text { Pengumpulan data dilakukan }
$$
melalui wawancara dan studi dokumen. Wawancara dalam penelitian ini menggunakan wawancara terstruktur. Dalam penelitian ini, peneliti menggunakan alat bantu untuk mengumpulkan data seperti pedoman wawancara, cheklist materi KRR serta telepon genggam untuk merekam sesi wawancara. Teknis analisis data yang digunakan dalam penelitian ini adalah analisis data kualitatif yaitu pengumpulan data, transkip data, pembuatan koding, kategorisasi data, penyimpulan sementara, triangulasi dan penyimpulan akhir (Irawan, 2006).

\section{HASIL}

\section{Gambaran Umum Tempat Penelitian}

SMPN 52 Surabaya terletak di Kota Surabaya bagian timur. SMP ini berada di Kelurahan Medokan Semampir, Kecamatan Sukolilo. SMP ini merupakan sekolah yang baru berdiri tahun 2011. Sekolah yang berdiri diatas lahan $5.000 \mathrm{~m}^{2}$ ini merupakan sekolah satu lokasi yang berada di bawah naungan Dinas Pendidikan Kota Surabaya. Jumlah guru SMPN 52 Surabaya adalah sebanyak 37 orang, sedangkan jumlah siswa sebanyak 770 siswa. Jumlah siswa tersebut tersebar di kelas VII, VIII dan IX. Rentang usia siswa SMP ini adalah 13-17 tahun. Sekolah ini telah menggunakan Kurikulum 2013 dalam pembelajaran.

Tabel 1. Karakteristik Informan

\begin{tabular}{ccc}
\hline Inisial & Usia (tahun) & Jabatan \\
\hline AT & 55 & Guru PKN \\
\hline MR & 55 & Guru Agama \\
\hline HN & 50 & Guru IPA \\
\hline PR & 49 & Guru PJOK \\
\hline AB & 15 & Siswa \\
\hline NS & 14 & Siswa \\
\hline
\end{tabular}


Karakteristik informan penelitian yang dipilih oleh peneliti terbagi menjadi dua jenis yaitu guru dan siswa. Guru mata pelajaran yang menjadi informan penelitian berpendidikan minimal sarjana. Seluruh informan guru belum pernah mendapatkan pelatihan mengenai kesehatan reproduksi remaja komprehensif. Siswa yang menjadi informan penelitian berasal dari kelas IX. Keterlibatan siswa bertujuan untuk triangulasi data penelitian yaitu mengklarifikasi jawaban dari guru mata pelajaran yang menjadi informan penelitian.

\section{Pemahaman Guru tentang Pendidikan KRR}

Berdasarkan hasil wawancara diketahui bahwa tidak semua informan mengetahui materi Kesehatan Reproduksi Remaja secara komprehensif. Guru mata pelajaran PKN, Agama, dan PJOK lebih cenderung mengaitkan kesehatan reproduksi remaja pada keadaan fisik, sedangkan KRR terkait pula pada aspek psikis, agama, nilai, norma, dan budaya. Berikut adalah cuplikan wawancara dengan informan AT dan MR:

"Hemm yang berkaitan dengan reproduksi ya.. libido ya.. apa ya mudah terangsang kalau lihat video atau lihat temannya seperti itu ya mbak." (AT, 55 Tahun).

"Ya ini pertanyaan sulit menurut saya. Kesehatan reproduksi remaja yang saya tahu itu berhubungan dengan kebersihan alat reprodusksi terutama kalau mau cebok gitu mana yang harus didahulukan, arahnya bagaimana. Berhubungan dengan alat reproduksinya gitu. Dan lagi kalau sebelum cebok tangannya lebih baik dicuci dulu, bisa jadi kotor ada kuman-kuman yang bisa masuk kedalam. Kemudian menstruasi, kalau menstruasi jangan sampai pembalut itu ditandon sampai lama sampai jadi sarang bakteri. Dan selama belum menikah ya jangan sampai terjadi perzinaan lah." (MR, 55 Tahun).
Informan HN sebagai guru IPA menyatakan bahwa kesehatan reproduksi remaja adalah segala hal yang berkaitan dengan organ reproduksi. Informan $\mathrm{HN}$ menyadari bahwa remaja memiliki ketertarikan mengenai berbagai hal yang berkaitan dengan reproduksi. Selain itu, $\mathrm{HN}$ juga menyadari bahwa seringkali remaja berperilaku tanpa memikirkan akibatnya. HN memberikan materi KRR lebih komprehensif dengan mengaitkan pada aspek fisik, psikis, agama, nilai, norma, dan budaya untuk meningkatkan pemahaman remaja mengenai kesehatan reproduksinya. HN berharap agar remaja mampu menghindari perilaku yang menyimpang. Berikut cuplikan wawancara dengan informan $\mathrm{HN}$ :

"Kesehatan reproduksi remaja ya yang berhubungan dengan organ reproduksi. Kalau perempuan ya berhubungan dengan vagina, laki-laki ya penis seperti itu. Kadang anak-anak itu tidak berfikir panjang, hanya berfikir sesaat jadi perlu untuk menjelaskan akibatnya. Contohnya, mereka melihat gambar, terus terangsang dan ingin mencoba. Jadi mereka tidak berfikir bahwa itu bisa menyebabkan kehamilan. Ya seperti itu tadi, dan pergaulan remaja bagaimana dengan lawan jenis $d s b$ perlu dijelaskan.... kemudian saya jelaskan juga dengan hadist.." (HN, 50 Tahun)

Setiap guru memiliki karakteristik tersendiri dalam menyampaikan pembelajaran. Beberapa guru seringkali memberikan nasehat pada siswanya. Menurut informan NS, guru yang paling sering memberikan nasehat saat pembelajaran adalah informan $\mathrm{HN}$ dan AT. Berikut cuplikan wawancara dengan informan tambahan:

"Bu HN itu kalau ngajar selalu ngingetin muridnya. Satu kata yang selalu saya ingat dari Bu HN itu, "nak, hidup itu adalah pilihan”. Bu HN itu selalu ngasihngasih ceramah agama agar anak-anak 
tidak nyelewang. Nah kalau Bu AT selalu ngajarin kedisiplinan, biar anak-anak itu tidak semena-mena sama orang yang lebih tua, kata-katanya dijaga" (NS, 14 tahun).

\section{Peran menyampaikan pendidikan KRR}

Seluruh informan menyadari peran dalam menyampaikan pendidikan KRR merupakan tanggung jawab dari berbagai pihak. Menurut informan dari pihak sekolah yang bertanggung jawab menyampaikan pendidikan ini adalah guru, dan juga kepala sekolah. Selain itu, pendidikan ini juga menjadi tanggung jawab dari orang tua, masyarakat, puskesmas, dinas kesehatan, dinas sosial, kepolisian, dan pemerintah. Namun beberapa guru masih merasa tabu saat menyampaikan materi ini. Berikut cuplikan wawancara dengan informan guru:

"Yang bertanggung jawab untuk memberikan materi mengenai KRR ini ya semuanya.. ya orang tua, guru, ya puskesmas dengan melakukan penyuluhan, pihak dinas kesehatan, kader UKS juga" (AT, 55 Tahun).

"Saya itu rasa tabunya itu ada, takut nya anak-anak itu mengartikan apa yang diajarkan salah, jadi saya mengajarkan yang tidak baik gitu lo. Kalau pendidikan itu baiknya dari keluarga, guru dan masyarakat" (MR, 55 Tahun).

“.. yang bertanggung jawab yang jelas ya biologi, agama, kemudian karena norma PKn seperti itu. Kalau lingkup sekolah ya kepala sekolah. Kalau lingkungan rumah yang berperan sekali itu ibu, yang kedua ayah" (HN, 50 Tahun).

"Kalau umum gitu kan kerjasamanya banyak mbak, dinas kesehatan, kepolisian, dinas sosial masuk juga mbak itu. Kalau di sekolah gini guru olahraga dan BK juga" (PR, 49 Tahun).

\section{Persepsi Guru terhadap materi KRR dalam Kurikulum}

Kurikulum memiliki peran penting dalam dunia pendidikan sebagai pedoman penyelenggaraan pembelajaran. Berdasarkan keterangan dari informan AT, MR dan PR materi KRR yang ada saat ini yang sudah cukup memadai, namun pada penyampaiannya guru perlu memberikan beberapa pengembangan. Berikut merupakan cuplikan wawancara dengan informan MR:

"Pendidikan KRR yang diajarkan sudah cukup mbak, tapi gak semuanya.... Mengenai reproduksi itu, yang termasuk dalam agama itu yang berhubungan dengan baligh, kewajiban, ya hukumhukum itu. ....kalau seperti pergaulan gitu termasuk dalam pengembangan. Ini biasanya menyangkut pergaulan itu pun tidak terlalu khusus materinya, tapi ya gurunya mengembangkan kemana-mana kayak gitu” (MR, 55 Tahun).

Sedangkan menurut informan $\mathrm{HN}$, pendidikan KRR dalam kurikulum masih belum memadai. Hal tersebut disebabkan semakin banyak masalah kesehatan reproduksi pada usia belia, sehingga pendidikan KRR perlu diajarkan lebih dini. Menurut informan $\mathrm{HN}$, pendidikan KRR yang diajarkan pada usia yang lebih dini dapat menurunkan permasalahan kesehatan reproduksi pada anak dan remaja. Berikut cuplikan wawancara dengan informan $\mathrm{HN}$ :

"Belum memadai mbak, sekarang gini, sebenarnya pendidikan itu kan di mulai dari SD. Lha ini SMP yang berhubungan dengan kespro itu ada di kelas IX. Sedangkan sekarang kejadian kayak pelecahan seksual, hubungan seksual itu sudah ada sejak usia belia. Usia 10 tahun sudah ada yang diperkosa, padahal anakanak itu juga nggak tahu itu apa maksudnya. Apalagi ada juga kejadian pada anak TK, itu kan sudah mengalami kejadian yang tidak pernah dia bayangkan 
karena meraka tidak tahu” (HN, 50 Tahun).

Selain itu informan $\mathrm{HN}$ menambahkan bahwa materi KRR dalam mata pelajaran IPA adalah mengenai anatomi dan fisiologi organ reproduksi dan cara perawatannnya. Menurut $\mathrm{HN}$ materi tersebut masih belum cukup untuk mencegah permasalahan remaja. Berdasarkan hal tersebut, informan $\mathrm{HN}$ memberikan tambahan informasi pada siswa untuk menambah pengetahuan siswa mengenai kesehatan reproduksi. Berikut cuplikan hasil wawancara dengan $\mathrm{HN}$ :

"Terkait KRR di materi kelas IX hanya menyebutkan tentang organ reproduksi fungsinya untuk ini dan cara merawatnya, seperti ganti celana dalam, tidak boleh lembab. Jadi saya mengantisipasinya (permasalahan kesehatan reproduksi) dengan mengajarkan lebih dalam " (HN, 50 Tahun).

Keterangan dari informan $\mathrm{HN}$ juga dibenarkan oleh informan $\mathrm{AB}$. Informan AB memiliki pendapat sebaiknya pendidikan diberikan lebih dini. Berikut cuplikan kuotasi dengan $\mathrm{AB}$ :

"Ya perlu. Paling enggak ya di kelas 6 lah. Soalnya di usia itu udah ada gejala-gejala pubertas" (AB, 15 Tahun).

Sebagian informan belum mengetahui bahwa materi KRR telah terdistribusi dalam berbagai mata pelajaran. Hal tersebut menunjukkan bahwa belum ada koordinasi antar guru mata pelajaran untuk menyampaikan materi KRR. Berikut cuplikan wawancara dengan informan AT:

“...pendidikan KRR kedepannya ya kalau bisa itu, disisipkan ke berbagai mata pelajaran, jadi biar anak-anak itu tahu lebih jauh. Agar kami guru-gurunya juga bisa memberikan pendidikan dengan lebih baik" (AT, 55 Tahun).
Peneliti melakukan studi dokumen terhadap Model Silabus Mata Pelajaran Sekolah Menengah Pertama/ Madrasah Tsanawiyah (SMP/MTs) Tahun 2017 untuk mengetahui distribusi materi KRR dalam mata pelajaran. Peneliti menggunakan Modul Pendidikan Kesehatan Reproduksi untuk Peserta Didik SMP/MTs sederajat sebagai acuan studi dokumen. Hasil studi dokumen menunjukkan bahwa tidak ada mata pelajaran yang khusus mengajarkan pendidikan kesehatan reproduksi komprehensif. Materi ini tersebar pada beberapa mata pelajaran. Namun tidak semua materi KRR dalam Modul Pendidikan Kesehatan Reproduksi untuk Peserta Didik SMP/MTs sederajat menjadi pokok bahasan dalam silabus mata pelajaran Kurikulum 2013. Distribusi Materi KRR pada beberapa mata pelajaran dapat dilihat pada tabel 2 .

\section{Penyampaian Materi KRR}

Berdasarkan hasil wawancara didapatkan hasil bahwa seluruh informan menggunakan metode ceramah, tanya jawab dan juga diskusi. Terkadang informan juga menggunakan media film untuk menyampaikan pendidikan. Informan AT juga menggunakan permainan dalam pembelajaran, sedangkan $\mathrm{HN}$ memisahkan laki-laki dan perempuan ketika mengajarkan materi KRR yang sensitif yaitu tentang sistem reproduksi manusia. Metode tersebut digunakan agar siswa tidak merasa malu saat pembelajaran. Berikut cuplikan wawancara dengan informan guru:

"Saya pakai metode ceramah, ya tanya jawab, diskusi. Kalau untuk reproduksi saya biasanya saya putarkan film pakai proyektor mengenai janin dalam kandungan dan juga saya contohkan apa yang mereka lihat, gitu aja" (MR, 55 Tahun). 
Tabel 2. Distribusi Materi KRR Pada Mata Pelajaran

\begin{tabular}{|c|c|}
\hline Materi & Mata pelajaran \\
\hline \multicolumn{2}{|c|}{ KONSEP UTAMA 1: Hubungan dengan Orang Lain } \\
\hline$\square$ Konsep diri & $\begin{array}{l}\text { PAI (kelasVII, VIII, IX), B. Indonesia (kelas } \\
\text { VIII, IX) }\end{array}$ \\
\hline$\square \quad$ Keluarga & PAI (kelas VII, VIII, IX), IPS (kelas IX) \\
\hline$\square \quad$ Pertemanan dan cinta kasih & PAI (kelas VII), PKN (kelas VII), IPS (kelas IX) \\
\hline$\square \quad$ Toleransi dan menghargai & $\begin{array}{l}\text { PAI (kelas VII, VIII, IX), PKN (kelas VII, IX), } \\
\text { IPS (kelas IX) }\end{array}$ \\
\hline$\square$ Pernikahan dan pengasuhan & - \\
\hline \multicolumn{2}{|c|}{ KONSEP UTAMA 2: Nilai, Sikap dan Keterampilan } \\
\hline$\square \quad$ Pemahaman, sikap dan nilai & $\begin{array}{l}\text { PAI (kelas VII, VIII,IX), PKN (kelas VII), IPS } \\
\text { (kelas IX) }\end{array}$ \\
\hline$\square \quad$ Menghadapi pengaruh teman sebaya & PJOK (kelas VIII), IPS (kelas IX) \\
\hline$\square \quad$ Mencari bantuan dan dukungan & IPS (kelas IX) \\
\hline \multicolumn{2}{|c|}{ KONSEP UTAMA 3: Budaya, Sosial dan Hak Asasi Manusia } \\
\hline$\square \quad$ Budaya dan hukum & $\begin{array}{l}\text { PKN (kelas VII,IX), IPS (kelas IX), Seni } \\
\text { Budaya }\end{array}$ \\
\hline$\square \quad$ Peran media & IPS (kelas IX), B. Indonesia (kelas VIII) \\
\hline$\square \quad$ Kesetaraan gender & - \\
\hline $\begin{array}{l}\text { Kekerasan berbasis seksual dan } \\
\text { gender }\end{array}$ & - \\
\hline \multicolumn{2}{|c|}{ KONSEP UTAMA 4: Kesehatan Reproduksi } \\
\hline$\square$ Pubertas & $\begin{array}{l}\text { IPA (kelas IX), PJOK (kelas VII), PAI (kelas } \\
\text { VII) }\end{array}$ \\
\hline$\square$ Reproduksi & IPA (kelas IX) \\
\hline \multicolumn{2}{|c|}{ KONSEP UTAMA 5: Infeksi Menular Seksual, HIV-AIDS dan NAPZA } \\
\hline$\square \quad$ Infeksi Menular Seksual & IPA (kelas IX) \\
\hline$\square$ HIV-AIDS & IPA (kelas IX) \\
\hline$\square \quad$ NAPZA & PAI (kelas VIII), IPA (kelas VIII) \\
\hline
\end{tabular}

Lainnya, sebutkan....

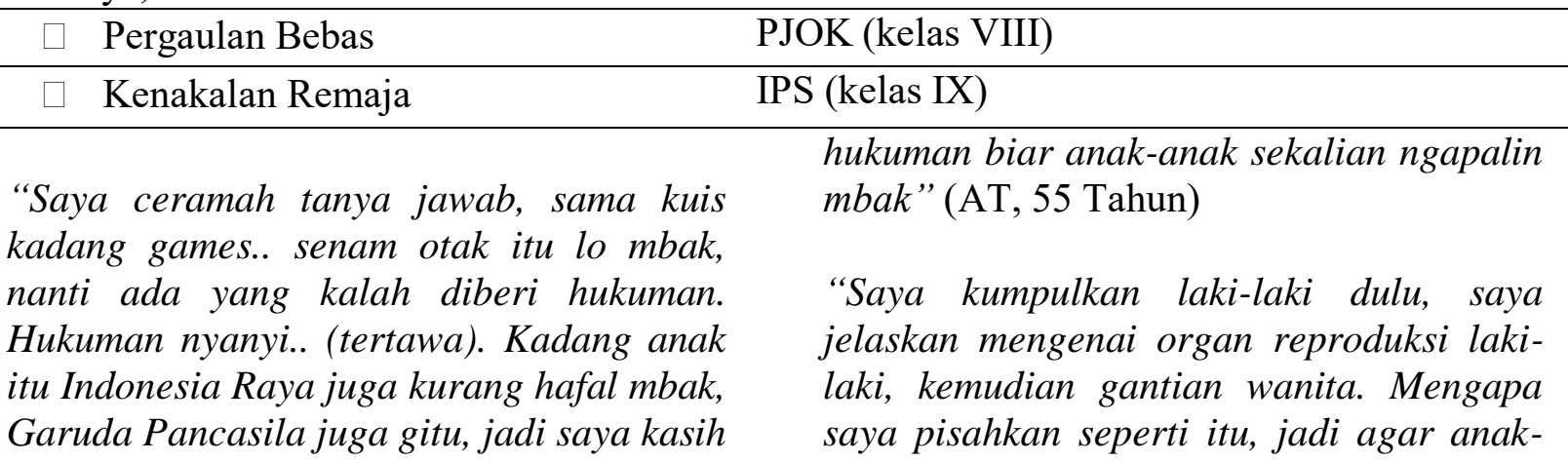


anak lebih tau inilah organ reproduksi mereka. Jadi mereka tidak malu dengan lawan jenis, begitu. Kalau materi yang keseluruhan di buku ada tapi hanya gambar animasi yang tidak vulgar. Begitu saya pisah yang laki sendiri, perempuan sendiri saya beri gambar aslinya, maksudnya ya gambar hidup. Tapi ya memang pertama kali gitu anak-anak ada rasa canggung, jadi tertawa gitu lo. Terus saya bilang gini, "jangan tertawa, itukan organ reproduksi mu sendiri”,'(HN, 50 Tahun).

Informan $\mathrm{AB}$ dan NS membenarkan bahwa metode yang sering digunakan oleh guru adalah ceramah tanya jawab, sedangkan informan $\mathrm{HN}$ memisahkan kelas antara laki-laki dan perempuan saat pembelajaran mengenai sistem reproduksi manusia. Seperti yang dituturkan oleh informan NS sebagai berikut:

“...biasanya dijelasin di depan kelas, kadang juga ditanya-tanya... Iya pernah di putarkan film juga.. Iya dipisah. Kan ngambil yang 2 jam, satu jam buat cewe, terus satu jam buat cowo. Semuanya di ajarin, alat reproduksinya perempuan sama laki-laki juga, kan kalau ujian keluar juga. Iya tapi membahasnya kalau perempuan lebih banyak tentang reproduksi perempuan. Jadi kita gak malu kalau mau tanya-tanya sama guru” (NS, 14 Tahun).

\section{PEMBAHASAN}

\section{Pemahaman Guru tentang Pendidikan KRR}

\footnotetext{
Sebagian besar informan kurang faham mengenai pendidikan KRR komprehensif. Informan merasa tabu dalam menyampaikan materi ini. Hal tersebut tidak sesuai dengan penelitian Hermiyanty, et al. (2016) yang menyatakan bahwa guru sebagai tenaga pendidik harus memiliki kemampuan untuk mengatur proses pembelajaran sesuai dengan kompetensi dasar yang berlaku.
}

Informan mengaku bahwa tidak pernah mendapatkan pelatihan mengenai pendidikan KRR, tidak adanya pelatihan membuat guru tidak dapat menyampaikan materi secara mendalam. Sedangkan penelitian Triyanto, et al. (2013) menyatakan bahwa pelatihan bukanlah satusatunya cara untuk mewujudkan proses pembelajaran yang efektif dan efisien. Selain mengikuti pelatihan mengenai pendidikan KRR, sekolah dapat meningkatkan kualitas pembelajaran dengan cara mendorong guru untuk meningkatkan pengetahuan dan profesionalisme dalam mengajar. Sekolah juga perlu mendorong guru untuk meningkatkan penggunaan media dalam pembelajaran. Selain itu sekolah harus melengkapi sarana-prasarana pembelajaran serta mengadakan pertemuan rutin antara guru-guru dengan kepala sekolah untuk meningkatkan kualitas pembelajaran.

\section{Peran menyampaikan pendidikan KRR}

Seluruh informan menyadari bahwa guru memiliki peran penting untuk menyampaikan pendidikan KRR. Hal tersebut sesuai dengan penelitian Maolinda, et al (2012) yang menyatakan bahwa pendidikan kesehatan reproduksi penting untuk dilaksanakan. Pendidikan ini merupakan hak reproduksi yang harus diterima remaja. Penelitian Wijayanti (2007) menyebutkan bahwa remaja mempunyai minat yang tinggi untuk mengetahui tentang kesehatan reproduksinya. Orang tua dan guru merupakan sumber yang paling baik dalam memberikan pendidikan ini. Hal ini dikarenakan orang tua dan guru adalah orang yang paling dekat dengan remaja serta dapat memberikan informasi yang benar dan tepat.

Namun beberapa informan utama merasa tabu untuk memberikan pendidikan ini. Informan utama tersebut menganggap 
bahwa materi KRR yang diajarkan dapat membuat siswa berperilaku menyimpang. Hal ini sesuai dengan penelitian Pakasi dan Kartikawati (2013) yang menyatakan bahwa guru memiliki anggapan bahwa pendidikan reproduksi merupakan suatu hal yang tabu untuk dibicarakan dengan siswa. Guru memiliki kekhawatiran bahwa pendidikan tersebut dapat meningkatkan rasa ingin tahu siswa dan mendorong mereka melakukan seks pranikah.

Guru memiliki peran utama dalam dunia pendidikan, hal tersebut dikarenakan guru berinteraksi langsung dengan siswa dalam memberikan pendidikan. Penelitian Setiawan (2013) menyatakan bahwa selain meningkatkan kemampuan akademik siswa, sekolah juga memiliki tujuan untuk membentuk karakter positif siswa. Sehingga tugas guru tidak hanya menyampaikan materi didalam kelas, namun juga membentuk siswa menjadi pribadi yang lebih baik. Guru juga memiliki pengaruh yang cukup besar pada pembentukan karakter, kecerdasan intelektual, sosial dan emosional peserta didik.

Disamping itu guru berpendapat bahwa pendidikan KRR merupakan tanggung jawab bersama antara orang tua, guru, masyarakat dan juga pemerintah. Hal tersebut sesuai dengan penelitian Farihah (2015) yang menyatakan bahwa pendidikan keluarga berkaitan dengan pembentukan perilaku positif anak didik. Penelitian Nursal (2008) menyebutkan bahwa seharusnya pertama kali pendidikan kesehatan reproduksi bagi anak disampaikan oleh orang tua. Orang tua dapat menjelaskan norma dan berbagai ketentuan mengenai hal-hal yang boleh atau tidak boleh dilakukan oleh sorang remaja. Menurut penelitian Anas (2010) lingkungan keluarga yang kondusif dan informatif diperlukan untuk meningkatkan kesehatan reproduksi remaja. Sebagian keluarga yang menganggap bahwa seks tabu untuk dibicarakan menyebabkan remaja enggan bertanya mengenai kesehatan reproduksi pada orang tuanya. Nursal (2008) juga menyatakan bahwa orang tua yang tertutup untuk membicarakan kesehatan reproduksi dengan anaknya dapat menyebabkan remaja mencari informasi menggunakan cara mereka sendiri, sedangkan informasi yang didapatkan remaja belum tentu benar. Hal tersebut merupakan penyebab terjerumusnya remaja pada perilaku beresiko. Selain itu penelitian Maolinda, et al (2012) juga menyebutkan bahwa pelaksanaan pendidikan ini memerlukan kerjasama dengan berbagai institusi, sehingga tidak hanya pengetahuan saja yang didapatkan, namun juga dukungan emosional dari seluruh pihak diharapkan bisa membentuk sikap positif remaja.

\section{Persepsi Guru terhadap materi KRR dalam Kurikulum}

Hasil wawancara menunjukkan bahwa materi KRR terdistribusi dalam berbagai mata pelajaran. Sebagian besar informan guru menilai materi KRR yang ada saat ini sudah memadai. Namun pada penyampaiannya perlu beberapa pengembangan oleh guru. Salah satu informan guru dan siswa menyatakan bahwa pendidikan KRR dalam kurikulum belum memadai. Hal tersebut dikarenakan semakin banyak masalah kesehatan reproduksi pada usia lebih dini. Hal tersebut sesuai dengan BKKBN (2013) yang menyatakan bahwa pendidikan KRR komprehensif dapat diberikan pada anakanak hingga remaja. Pendidikan KRR pada anak-anak dapat dimulai pada usia 5 tahun. Penelitian Bella dan Istianah (2017) menyebutkan bahwa cara melindungi anak dari penyimpangan seksual dapat dilakukan melalui pendidikan kesehatan reproduksi yang terstruktur dengan baik. Selain itu Bella dan Istianah (2017) menyampaikan bahwa keterlibatan lingkungan sekolah dan lingkungan keluarga sangat diperlukan untuk mencapai keberhasilan pendidikan kesehatan reproduksi komprehensif.

Kurikulum memiliki fungsi untuk mencapai tujuan pendidikan, sehingga 
kurikulum merupakan acuan dalam kegiatan belajar-mengajar. Salah satu pertimbangan dalam penyusunan kurikulum adalah keadaan dan perkembangan peserta didik. Masalah kesehatan reproduksi remaja yang semakin banyak memerlukan upaya pencegahan yang terpadu, salah satunya adalah pendidikan KRR di sekolah. Adanya pendidikan KRR di sekolah memudahkan remaja mendapatkan informasi mengenai kesehatan reproduksi yang sesuai dan bertanggungjawab. Materi KRR yang dimasukkan dalam kurikulum tentunya akan mencegah remaja mendapatkan informasi yang menyesatkan, sehingga remaja dapat lebih bertanggung jawab atas kesehatan reproduksinya. Studi dokumen yang dilakukan peneliti menyatakan bahwa tidak semua materi KRR menjadi pokok bahasan dalam mata pelajaran Kurikulum 2013. Hal tersebut sesuai dengan penelitian dari Wardani, et al (2006), yang menyatakan bahwa pendidikan kesehatan reproduksi sudah diajarkan namun belum maksimal. Pengajaran materi kesehatan reproduksi disisipkan ke dalam beberapa mata pelajaran yang mengajarkan aspek fisik dan sosial seperti biologi, penjaskes, agama, serta kegiatan ekstrakurikuler.

\section{Penyampaian Materi KRR}

Penampilan guru di kelas merupakan salah satu hal yang paling penting untuk menyampaikan pelajaran. Oleh karena itu, kemampuan guru dalam menyampaikan materi sangat dibutuhkan agar siswa tidak merasa tabu dan terbuka saat proses pembelajaran. Hampir seluruh informan utama menggunakan metode ceramah, tanya jawab dan juga diskusi saat pembelajaran dalam kelas, selain itu beberapa informan utama juga menggunakan permainan dan pemutaran video. Hal tersebut sesuai dengan pernyataan Notoadmodjo (2007) yang menyebutkan bahwa pendidikan kesehatan reproduksi berkelompok dapat dilakukan melalui beberapa metode antara lain metode ceramah, diskusi kelompok, curah pendapat, dan permainan simulasi. Metode pendidikan bertujuan agar tercipta suasana belajar yang menyenangkan sehingga siswa mampu mengikuti pelajaran dengan maksimal. Untuk meningkatkan semangat siswa dalam belajar, informan perlu menerapkan metode belajar yang sesuai dengan karakteristik siswa.

Salah satu karakteristik siswa adalah merasa malu saat membahas materi KRR yang sensitif yaitu tentang sistem reproduksi manusia. Hal tersebut sesuai dengan penelitian Wulandari, et al. Wulandari, et al (2012) menyatakan bahwa seringkali siswa merasa tidak nyaman atau tabu untuk membicarakan masalah kesehatan reproduksi dan seksualitas, namun karena rasa ingin tahu siswa cukup besar maka mereka akan berusaha untuk mendapatkan informasi ini. Untuk mengatasi rasa tidak nyaman dan tabu tersebut, salah satu informan SMPN 52 Surabaya memisahkan laki-laki dan perempuan saat pembelajaran. Hal tersebut sesuai dengan penelitian Masdudi (2013) yang menyatakan bahwa sebelum memulai pembelajaran guru terlebih dahulu harus mengenal karakteristik masing-masing siswanya agar guru lebih mudah menyampaikan materi pelajaran pada siswa dan mampu mengantisipasi segala perubahan yang terjadi pada perilaku belajar siswa, sehingga proses pembelajaran dapat tercapai sesuai yang diharapkan.

Memisahkan kelas antara laki-laki dan perempuan pada pembelajaran sistem reproduksi manusia ternyata mampu membuat siswa terbuka dan lebih aktif dalam proses pembelajaran. Hal tersebut sesuai dengan penelitian Azhar (2013) yang menyatakan bahwa penggunaan metode yang baik dimaknai apabila metode tersebut dapat menciptakan interaksi antara siswa dengan guru. Metode pembelajaran yang baik dapat membuat siswa tertarik untuk belajar, memotivasi siswa bertanya dan meningkatkan keaktifan siswa dalam pembelajaran. 


\section{SIMPULAN}

Tidak semua informan memahami pendidikan KRR komprehensif, namun seluruh informan menyatakan bahwa pendidikan KRR penting untuk disampaikan. Beberapa informan merasa tabu dan kurang mampu untuk menyampaikan pendidikan KRR, hal tersebut dapat disebabkan karena belum adanya pelatihan dari pemerintah mengenai pendidikan ini. Materi KRR terdistribusi pada beberapa mata pelajaran, namun ada beberapa materi KRR yang tidak terdapat dalam kurikulum serta belum ada koordinasi antar guru mata pelajaran mengenai materi KRR sehingga informan menyampaikan materi dengan beberapa pengembangan pribadi. Penyampaian materi KRR dilakukan dengan berbagai metode, salah satu guru SMPN 52 Surabaya memisahkan laki-laki dan perempuan saat pemberian materi yang sensitif. Metode tersebut terbukti dapat meningkatkan keaktifan siswa untuk bertanya dan berdiskusi lebih dalam dengan guru.

Keberhasilan pendidikan KRR ini perlu kerjasama antara orang tua, guru, masyarakat dan pemerintah. Sekolah perlu bekerjasama dengan orang tua, agar orang tua selalu mengaawasi dan membimbing anaknya. Sekolah dapat bekerjasama dengan Puskesmas dan dinas pendidikan setempat agar memberikan sosialisasi mengenai Kesehatan Reproduksi Remaja pada tenaga pendidik (guru). Sedangkan pemerintah dapat memberikan sosialisasi dan pelatihan Pendidikan Kesehatan Reproduksi Remaja Komprehensif bagi guru serta menyesuaikan materi Pendidikan Kesehatan Reproduksi Remaja dalam kurikulum dengan keadaan remaja saat ini. Selain itu masyarakat dapat memberikan pengawasan pada remaja di lingkungannya.

\section{DAFTAR PUSTAKA}

Anas, S.H., 2010. Sketsa Kesehatan Reproduksi Remaja. Jurnal Studi Gender \& Anak, 5 (1).
Azhar, S.K., Daharnis, Sukmawati, I., 2013. Persepsi Siswa Tentang Layanan Informasi Kesehatan Reproduksi Remaja yang diberikan Guru BK SMAN 1 Kubung. Jurnal Ilmiah Konseling, 2 (1).

Bella, S.M., and Istianah, F., 2017. Pendidikan Seksualitas Sejak Dini sebagai Upaya Menghindarkan Anak-Anak Usia Sekolah Dasar dari Penyimpangan Seksualitas. Jurnal Penelitian Pendidikan Guru Sekolah Dasar, 5 (3).

BKKBN, 2013. Bimbingan Teknis Kesehaan Reproduksi dan Seksualitas yang Komprehensif. Jakarta: BKKBN

Farihah. 2015. Pengetahuan Kesehatan Reproduksi Remaja Melalui Pendidikan Keluarga. Jurnal Keluarga Sehat Sejahtera, 13 (26).

Hermiyanty, Hasanah, and Setiawan, H., 2016. Implementasi Pendidikan Kesehatan Reproduksi Remaja dalam Kurikulum Pendidikan Jasmani Olahraga dan Kesehatan di Sekolah Menengah Atas Kota Palu. Jurnal Kesehatan Tadulako, 2 (1).

Irawan, P., 2006. Penelitian Kualtatif dan Kuantitatif Untuk Ilmu-ilmu Sosial. Jakarta: Universitas Indonesia

Kementrian Kesehatan RI, 2015. Infodatin Pusat Data dan Informasi Kesehatan Reproduksi Remaja. Jakarta.

Kementrian Pendidikan dan Kebudayaan, Kementrian Kesehatan, Kementrian Agama, United Nations Population Fund (UNFPA), 2014. Modul Pendidikan Kesehatan Reproduksi untuk Peserta Didik SMP/MTs dan Sederajat. Jakarta.

KPAI. 2016. Rincian Data Kasus Berdasarkan Klaster Perlindungan Anak, 2011-2016.

Maolinda, N., Sriati, A., and Maryati, I., 2012. Hubungan Pengetahuan dengan Sikap Siswa Terhadap Pendidikan Kesehatan Reproduksi 
Remaja di SMAN 1 Mergahayu. Jurnal Unpad, 1 (1).

Masdudi. 2013. Karakteristik Perilaku Sosial Siswa dalam Proses pendidikan. Jurnal Pendidikan Sosial \& Ekonomi, 2(1)

Notoatmodjo, S., 2007. Kesehatan Masyarakat Ilmu dan Seni. Jakarta: Rineka Cipta.

Noviana, I., 2015. Kekerasan Seksual Terhadap Anak: Dampak Dan Penanganannya Child Sexual Abuse: Impact And Hendling. Jurnal Sosio Informa, 1(1).

Nursal, D. G. A., 2008. Faktor-Faktor yang Berhubungan dengan Perilaku Seksual Murid SMU Negeri di Kota Padang Tahun 2007. Jurnal Kesehatan Masyarakat, 2 (2).

Pakasi, T.D., and Kartikawati, R., 2013. Antara Kebutuhan dan Tabu: Pendidikan Seksualitas dan Kesehatan Reproduksi bagi Remaja di SMA. Jurnal Makara Seri Kesehatan, 17(2).

Setiawan, D., 2013. Peran Pendidikan Karakter Dalam Mengembangkan Kecerdasan Moral. Jurnal Pendidikan Karakter, 3 (1).

Triyanto, E., Anitah, S., and Suryani, N.,
2013. Peran Kepemimpinan Kepaia Sekoiah daiam Pemanfaatan Media Pembelajaran sebagai Upaya Peningkatan Kuautas Proses Pembelajaran. Jurnal Teknologi Pendidikan, 1(2).

Utomo, I. D., McDonald, P., 2009. Adolescent reproductive health in Indonesia: contested values and policy inaction. Studies in Family Planning Journal, 40 (2).

Wardani, ., et al., Tim Litbang Pusat Studi Seksualitas KPBI DIY., 2006. Pendidikan Kesehatan Reproduksi di Sekolah (Riset Kebijakan dan Pengembagan Kurikulum Kespro). Jurnal Bening, 7 (1).

Wijayanti,R., Swasti, K.G., and Rahayu, E., 2007. Hubungan Tingkat Pengetahuan Kesehatan Reproduksi Terhadap Perilaku Seksual Remaja Pada Siswa SMA di Kecamatan Baturraden dan Purwokerto. Jurnal Keperawatan Soedirman, 2(2).

Wulandari, V.F., Nirwana, H., and Nurfarhanah. 2012. Pemahaman Siswa Mengenai Kesehatan Reproduksi Remaja Melalui Layanan Informasi. Jurnal Ilmiah Konseling, 1(1). 